\title{
"É MINHA FILHA, TUDO FUI EU QUEM FIZ!" REFLEXÕES SOBRE A ARQUITETURA INTUITIVA DE MAMETU MUIANDE
}

\author{
Aisha - A. L. Diéne ${ }^{1}$
}

DOI 10.26512/revistacalundu.v4i1.32233

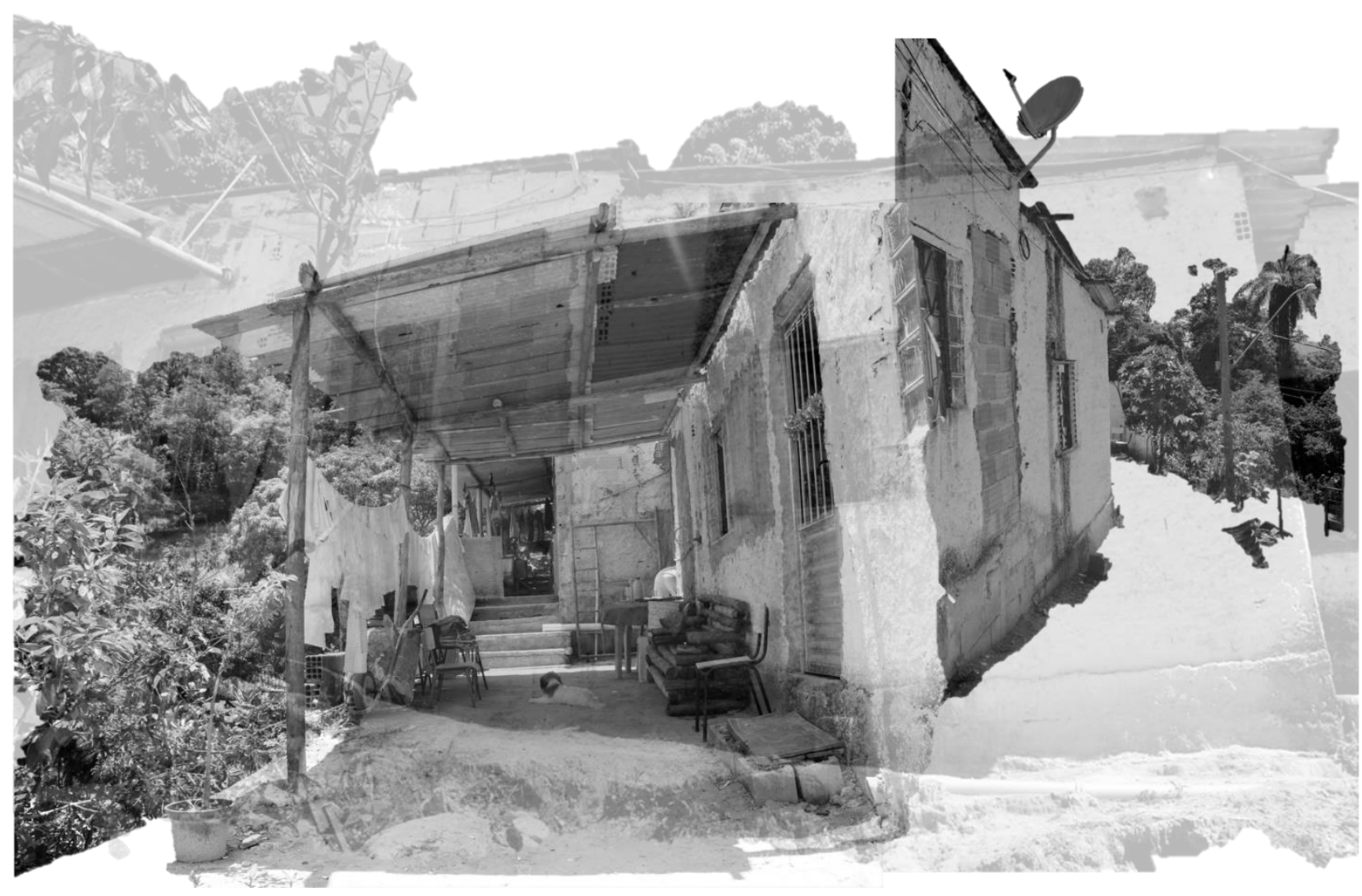

1 Arquiteta e Urbanista (CAU n ${ }^{\circ}$ A153871-3) graduada pelo Centro Universitário de Brasília UniCEUB, Mestranda em Antropologia Social - PPGAS/DAN/UnB; integrante do corpo editorial da Revista Calundu (http://periodicos.unb.br/index.php/revistacalundu/index), do Laboratório Matula: Sociabilidades, Diferenças e Desigualdades - CNPQ/PPGAS/DAN/UNB e candomblecista Ndanji Tumba Junsara. aisha.diene@gmail.com 


\begin{abstract}
Resumo
À vista do que se costuma chamar no trabalho de campo antropológico de entrevista, o texto aborda esse conceito de uma forma diferente que seja, talvez, a maneira pela qual segue a temporalidade das religiões afro-brasileiras. Não a relativização do tempo, mas a leitura dele por um espectro ocidental, como a chave que tranca ou destranca uma porta que se encontra no limiar acerca do "tempo do outro", segundo Johannes Fabian. Essa metodologia de pesquisa introduz o que descrevo como conversas trocadas em substituição a análises antropológicas. De maneira que tais conversas demonstram a relação da matriarca e Mãe de Santo Mametu Muiandê com a sua residência, a partir do que digo ser uma arquivivência - das escritas descritas nas paredes do que ela chama de sua casa -, à luz do que conceitua Conceição Evaristo. Modelado não somente pela vivência, mas também pelo aspecto ontológico que se mostra sua essência.
\end{abstract}

Palavras - chave: Candomblé. Conversa. Casa. Mãe de Santo.

\title{
“É MINHA FILHA, TUDO FUI EU QUEM FIZ!" REFLEXIONES SOBRE LA ARQUITECTURA INTUITIVA DE MAMETU MUIANDE
}

\begin{abstract}
Resumen
Teniendo en cuenta lo que normalmente se llama en el trabajo de campo antropológico de entrevista, el texto aborda este concepto de una manera diferente que es, tal vez, la forma en que sigue la temporalidad de las religiones afrobrasileñas. No la relativización del tiempo, sino la lectura del mismo por un espectro occidental, como la llave que cierra o abre una puerta que se encuentra en el umbral sobre el "tiempo del otro", según Johannes Fabian. Esta metodología de investigación introduce lo que describo como conversaciones intercambiadas en lugar de análisis antropológico. Para que tales conversaciones demuestren la relación de la matriarca y la Madre de Santo Mametu Muiandê con su residencia, de lo que digo es un arquitexperiencia - de los escritos descritos en las paredes de lo que ella llama su hogar -, considerando lo que Conceição Evaristo conceptualiza. Modelado no sólo por la experiencia, sino también por el aspecto ontológico que se muestra su esencia.
\end{abstract}

Palabras - clave: Candomblé. Conversación. Casa. Madre de Santo.

\section{Introdução}

Grande parte dos terreiros de candomblé no contexto brasileiro se fixam em áreas mais afastadas do perímetro urbano, claro que ao longo do processo historiográfico de crescimento da população e o consequente adensamento urbano ${ }^{2}$,

\footnotetext{
${ }^{2}$ Ocupação de forma intensa e geralmente, "desordenada" do solo.
} 
esses espaços foram em sua maioria "fagocitados"3, sendo necessária a mudança de local desses terrei(tórios); salvo os casos em que esse processo de ocupação acelerado, a intolerância religiosa transfigurada de alvará ou a especulação imobiliária, ainda não os alcançaram. O terreiro é um território que faz parte do que compõe os indivíduos que o vivem, nesse contexto, corpo, "terra, território e territorialidade" são indissociáveis, como bem define Beatriz Nascimento: "A terra é o meu quilombo. Meu espaço é meu quilombo. Onde eu estou, eu estou. Quando eu estou, eu sou. (1989)." (RATTS, 2006; p.59).

À vista dessa configuração, o terreiro Manzo Ngunzo Kaiango, hoje localizado no município de Santa Luzia, região metropolitana de Belo Horizonte/MG, nos ilustra o plano de fundo da arquivivência ${ }^{4}$ de Mãe Efigênia e sua família, protagonistas de um longo processo de reconhecimento enquanto comunidade quilombola ${ }^{5}$ no que perpassa a redefinição histórica do termo-conceito, muito distante daquela ideia arqueológica, "frigorificada" e engessada pela cultura e estrutura social "ainda" colonial (ALMEIDA, 2002; p.47). De maneira que, no ano de 2007 a comunidade foi reconhecida como comunidade Remanescente de Quilombo pela Fundação Cultural Palmares, passando em 2011, pelo doloroso caso de intolerância religiosa, onde o prefeito à frente na ocasião, autorizou a destruição de toda "a parte religiosa" da comunidade (Barracão e cozinha de santo), alegando risco de desabamento. Esse lote com $527 \mathrm{~m}^{2}$, no bairro de Santa Efigênia/Paraíso, abrigava a residência da matriarca e mais 11 famílias - todos ligados de forma consanguínea com a mesma.

Ocupado desde a década de 1970, as atividades religiosas tiveram início com a umbanda em um espaço dentro desse grande lote, chamado Senzala de Pai Benedito, e só posteriormente se configurou como Terreiro de Candomblé.

Durante o processo de desocupação e derrubada, as atividades religiosas foram interrompidas e a família retirada do seu terrei(tório) e encaminhada à um abrigo por cerca de 9 meses. Nesse período, Mãe Efigênia também conhecida como Mametu Muiandê, resolveu dar continuidade aos seus cultos em um terreno que havia comprado

\footnotetext{
3 Uma analogia ao processo biológico pelo qual uma célula engole através de suas membranas plasmáticas, partículas, bactérias, pedaços de tecido necrosado, o que gera um novo compartimento interno dentro dessa célula, chamado "fagossoma".

4 "no fundamento da narrativa de Becos, está uma vivência, que foi minha e dos meus" (EVARISTO, 2017; p.11), uma correspondência ao que a Conceição denomina de "escrevivência". Nesse caso, a arquitetura observada expressa as marcas das mudanças de hábitos, a partir da trajetória de vida de Mãe Efigênia.

5 MARQUES, Carlos Eduardo et al. Bandeira Branca em Pau Forte: a Senzala de Pai Benedito e o Quilomblé urbano de Manzo Ngunzo Kaiango, 2015.
} 
muitos anos antes do ocorrido, no município de Santa Luzia, onde reside e permanecem as atividades religiosas até hoje.

\section{Para o povo de santo: Uma conversa...}

O antropólogo que pesquisa as religiões afro-brasileiras dificilmente realiza sua observação participante sem causar ou ser envolvido nos conflitos e rivalidades que caracterizam a vida cotidiana dos terreiros. $O$ antropólogo vai aprendendo, assim, qual o grau adequado de proximidade e distância que deve manter na convivência cotidiana com os grupos, e nem sempre os preceitos malinowskianos de buscar uma intimidade total com os observados pode ser uma boa estratégia.

(SILVA, 2015, p.38).

Os diálogos descritos no decorrer desse texto são reflexões iniciais de um trabalho de campo, ocorrido entre os anos de 2019 e 2020. De forma que a metodologia desenvolvida se baseou em conversas obtidas informalmente com Mametu Muiandê e sua filha carnal Makota Kidoialê, também conhecida por Cássia.

Poderia denominar essas conversas como entrevistas, mas, essa palavra me faz refletir que mesmo de forma não pretenciosa, é estruturado um roteiro a ser seguido de acordo com as informações que serão relevantes ao meu trabalho de campo ou à minha pesquisa. Aquela ideia de que a informação é coletada e a minha pesquisa é garantida! Ironia, ao contrário do que Malinowski (1976; p.37) demonstrou como uma nova metodologia etnográfica, a exitosa observação participante se faz necessária ser adaptada no terreiro de candomblé.

Para se ter acesso à informação, por exemplo, é basilar não somente perceber os grupos por onde a informação circula, mas também quais são as informações que circulam nesses grupos, de maneira que se identifique quem serão os possíveis interlocutores. Não deixando de ser importante também ressaltar o equilíbrio necessário entre “'proximidade' e 'distância' que o antropólogo deve procurar manter para 'sobreviver' sob as políticas dos terreiros." (SILVA, 2015; p.39).

Como bem nos ilustra Wagner Gonçalves da Silva (2015) em $O$ antropólogo e sua magia: trabalho de campo e texto etnográfico nas pesquisas antropológicas sobre as religiões afro-brasileiras, ao discorrer sobre os problemas encontrados ao longo do trabalho de campo na escolha dos interlocutores por alguns antropólogos: 
Assim, embora as lições de metodologia nos orientem a coletar depoimentos representativos do maior número possível dos segmentos sociais que compõem as sociedades ou grupos observados, nem sempre isso é possível. A experiência mostra que o próprio campo condiciona o que observar e a quem. Nas religiões afro-brasileiras, a estrutura hierárquica que localiza as pessoas por sua senioridade iniciática, cargo e importância no grupo dificulta um diálogo indiferenciado do antropólogo com todas as pessoas do terreiro, ao menos de forma explícita ou oficial. (SILVA, 2015; p.39).

Mas voltando ao que reflito ser uma conversa, o povo de santo ${ }^{6}$ - onde também me incluo, no que perpassa pela lógica de ser pesquisadora e iniciada nessa religião têm sua forma de permitir que pesquisadores/curiosos que buscam informações sobre seus modos e costumes, adentrem seu terrei(tório). Nesse cenário, o tempo é outro ${ }^{7}$ !

Essa reflexão sobre a temporalidade no pensamento antropológico da sociedade atual é definida por Johannes Fabian (2013) como "alocrônico" em O Tempo e o Outro: como a antropologia estabelece seu objeto. De maneira que, esse "alocronismo fundacional da antropologia" é percebido como um problema permanente e de fato latente nas metodologias etnográficas. É o tempo do outro!

Antes de mais nada, o fato de parecer possível recusar a coetaneidade a outra pessoa, ou a outros povos, sugere que a coetaneidade não é nem um fato transcultural nem uma condição transcendental do conhecimento. O termo coetaneidade foi escolhido para assinalar um pressuposto central, ou seja, o de que todas as relações temporais e, portanto, a contemporaneidade, estão embutidas na práxis culturalmente organizada (FABIAN, 2013; p.69).

\section{Makota Kidoialê}

Bairro Santa Efigênia/BH, 2019.

Diante do imenso portão de ferro alaranjado que recobria a fachada da casa de Makota Cássia, ela me recebe e me convida para entrar em sua residência. Logo me apresenta ao seu cônjuge e à sua filha, que estavam na varanda ao lado da sala de estar, tentando parafusar uma rede na parede. Aguardo sentada no sofá a água que me foi

\footnotetext{
${ }^{6}$ Me refiro aqui à toda comunidade religiosa do candomblé que se intitula pertencente a essa religião dessa maneira.

${ }^{7}$ Ler DIÉNE, A. A. L.; AHUALLI, I. F. LUGAR DE MAIS VELHXS - Uma observação fenomenológica dos limites espaciais no terreiro de candomblé Tumba Nzo Jimona dia Nzambi. 2019.
} 
oferecida, enquanto observo sua residência e a dinâmica dos seus familiares ao mesmo tempo em que pai e filha brincam tentando parafusar a rede nova na parede da varanda.

Assim falamos do quão quente estava a cidade por conta da época das queimadas, enquanto ríamos do barulho que a furadeira fazia vez ou outra durante a prosa. Nessa deixa, ela me relata um pouco sobre a experiência de morar naquele espaço novo e que ainda estava em processo de obra, dizendo o quão "estranho" era se mudar para um espaço onde "não se sentia pertencente", porém sendo agora a "sua residência", refletindo sobre a relação do espaço em que se mora com o reflexo da personalidade da família que o habita (HEIDEGGER, 1954; p.6).

Sentada no sofá com as mãos apoiadas entre as pernas, Makota me relata de como tem sido diferente morar em um lugar novo somente com seu cônjuge e seus filhos, depois de tanto tempo habitando um espaço dentro do quilombo urbano Manzo e tão próximo ao terreiro de candomblé. E finalizou dizendo que seguia modificando e decorando a casa até que tivesse a sua "cara". Percebi que ela queria mais me escutar, do que falar. Assim, comecei a falar um pouco sobre mim: quem eu era, o que eu estudava e o que me levou até ali, a querer conhecer um pouco sobre o terreiro e comunidade quilombola da qual ela era a porta voz. Desse modo, ao falar que eu era Arquiteta e Urbanista de formação acadêmica, ela começou a me descrever a residência de Mãe Efigênia, localizada algumas ruas abaixo da que ela mora. De forma nostálgica, disse que sua mãe "escavou o terreno e construiu a casa onde moravam, por ser mais fácil escavar do que ir buscar pedras para aterrar”. Mãe Efigênia em meados da década de 1970, construiu a moradia que abrigaria toda a família até o momento da intervenção da prefeitura. E curiosamente, pontuou que sua "mãe tinha um costume de mudar as portas de lugar da casa várias vezes ao longo do ano, dizendo que "precisava circular a energia da casa" de tempos em tempos e que isso impedia ter má sorte dentro na residência". Brincando, a Makota nomeou essa tecnologia intuitiva construtiva de "Tecnologia Africana". 


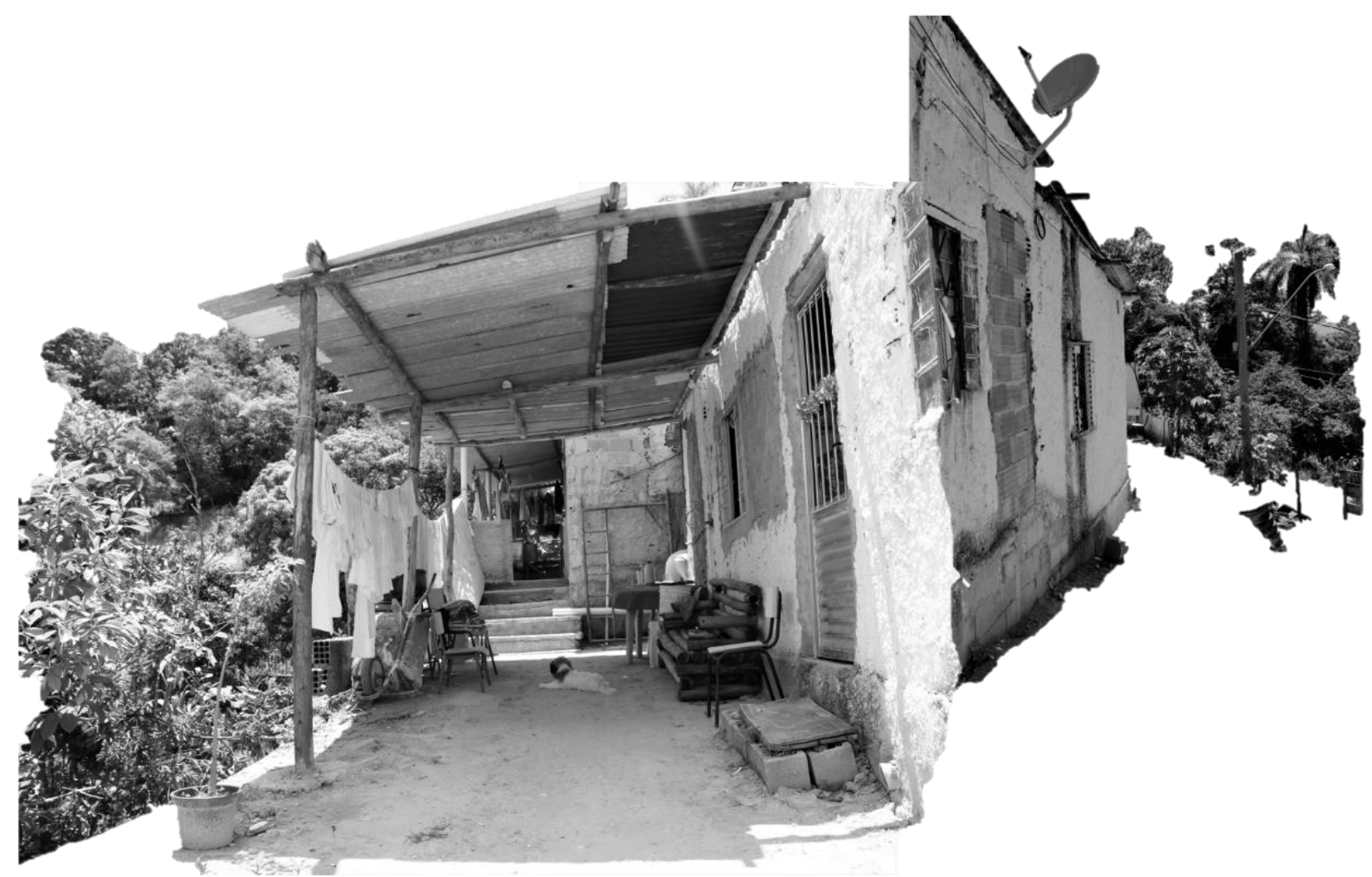

Figura 1- Colagem: "Duas perspectivas: da varanda da casa de Mametu Miandê e uma parte do Barracão do Terreiro Manzo Ngunzo Kaiango”

Esse costume que faz parte da maneira pela qual a matriarca se relaciona com o ambiente e o espaço que ela chama de "casa", nos mostra através do que resolvi nomear de arquivivência, como o espaço é mutável e modelado pelo indivíduo que o vive. Todas as esquadrias de portas e janelas que foram realocadas de tempos em tempos por Mametu Muiandê ficam expostas. Não se demonstra nenhuma preocupação em recobrir ou pintar aquele espaço que acomodava uma porta que foi trocada de lugar, esse espaço se mantém com tijolos aparentes, como cicatrizes que contam as aventuras de suas marcas (SEGAUD, 2016; p.217).

\section{Mametu Muiandê}

Bairro Santa Luzia/DF, 2020.

$\mathrm{Na}$ subida de uma rua bem íngreme em uma estrada de terra, se avistava o terreiro Manzo Ngunzo Kaingo, praticamente de esquina e sem identificação na fachada principal - objeto muito comum na vista frontal desses terrei(tórios). Já era noite quando cheguei com Makota Cássia, uns cachorros e alguns gritos de crianças saudosas nos 
recebiam na entrada. Subimos por uma porta lateral, que dava acesso até a parte mais alta, acima do nível da rua, onde acomodava a casa de Mãe Efigênia e de alguns outros familiares. Essa passagem lateral pela qual entramos que também dava acesso à parte religiosa ilustrou a sutil separação no uso dos espaços, de maneira que para se adentrar pela entrada principal das atividades religiosas seria necessário subir um pouco mais a rua enladeirada.

Sentada em uma cadeira, Mametu Muiandê conversava em uma roda com outras pessoas que aparentavam ser mais velhas dentro da hierarquia do candomblé. Naquele momento, percebi o contexto e cumprimentei de longe até o momento que Makota Cássia me convidou para ir até lá me apresentar.

Sentei e me apresentei. Apesar da dificuldade em prosseguir com o diálogo, uma vez que a todo o momento alguém interpelava e perguntava algo à Mametu sobre questões do terreiro ou soltava uma piada e se perdia o foco da fala, aguardei de forma respeitosa e paciente. Até que Mametu fez um sinal com a cabeça de que estava ciente de quem eu era e o que eu estava fazendo ali. Assim, ela deu o desfecho da conversa e rapidamente Makota me convidou para conhecer a parte da varanda, uma área coberta em frente à casa de Mãe Efigênia que ficava acoplada no mesmo terreno que o terreiro de candomblé.

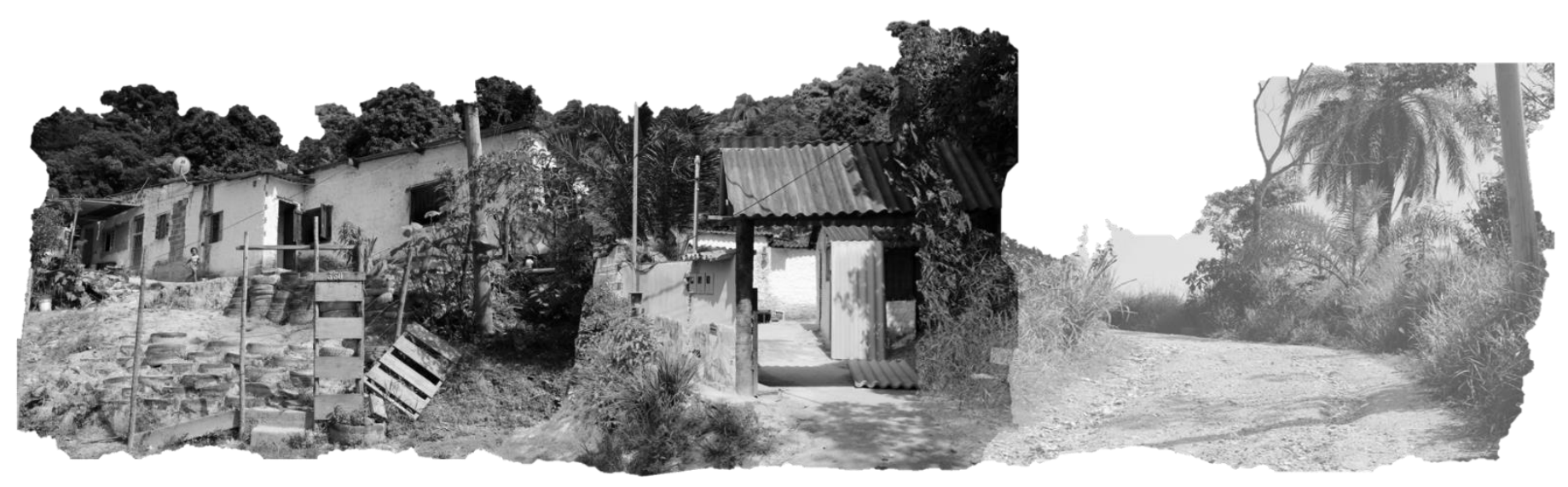

Figura 2- Colagem: "Vista panorâmica das fachadas"

\section{"É, essa é a minha casa, filha"}

Em uma breve análise da tipologia construtiva manifestada na Arquitetura desse espaço, perpasso pela lógica espacial das construções religiosas como barracão, cozinha e casas de santo, mas me volto para o breve entendimento da dinâmica interna da 
residência de Mametu para o desenrolar desse texto, através do que denominei de arquivivência.

As edificações religiosas como barracão, algumas casas de santo, cozinha e a residência em estudo são em alvenaria com e sem reboco, algumas com fissuras, rachaduras, pintadas interna e externamente com cal e cobertas com telhas de fribrocimento. De maneira geral, essas edificações apresentam um estado de conservação um tanto gasto, com esquadrias em madeira e metal, em que o piso, embora seja em cimento sem acabamento, cimento queimado ou cerâmica, ainda assim não apresenta tanto desgaste.

A residência em que Mametu reside é simples e funcional, feita em concreto armado sendo perceptível em suas paredes as partes não rebocadas, com tijolos aparentes, demonstrando a substituição de antigas portas e janelas. Apesar da estética compacta, a pequena casa acomoda 6 cômodos sendo: 2 quartos, 1 banheiro, 1 cozinha, sala de jantar e de estar, com varanda e lavanderia na área externa.

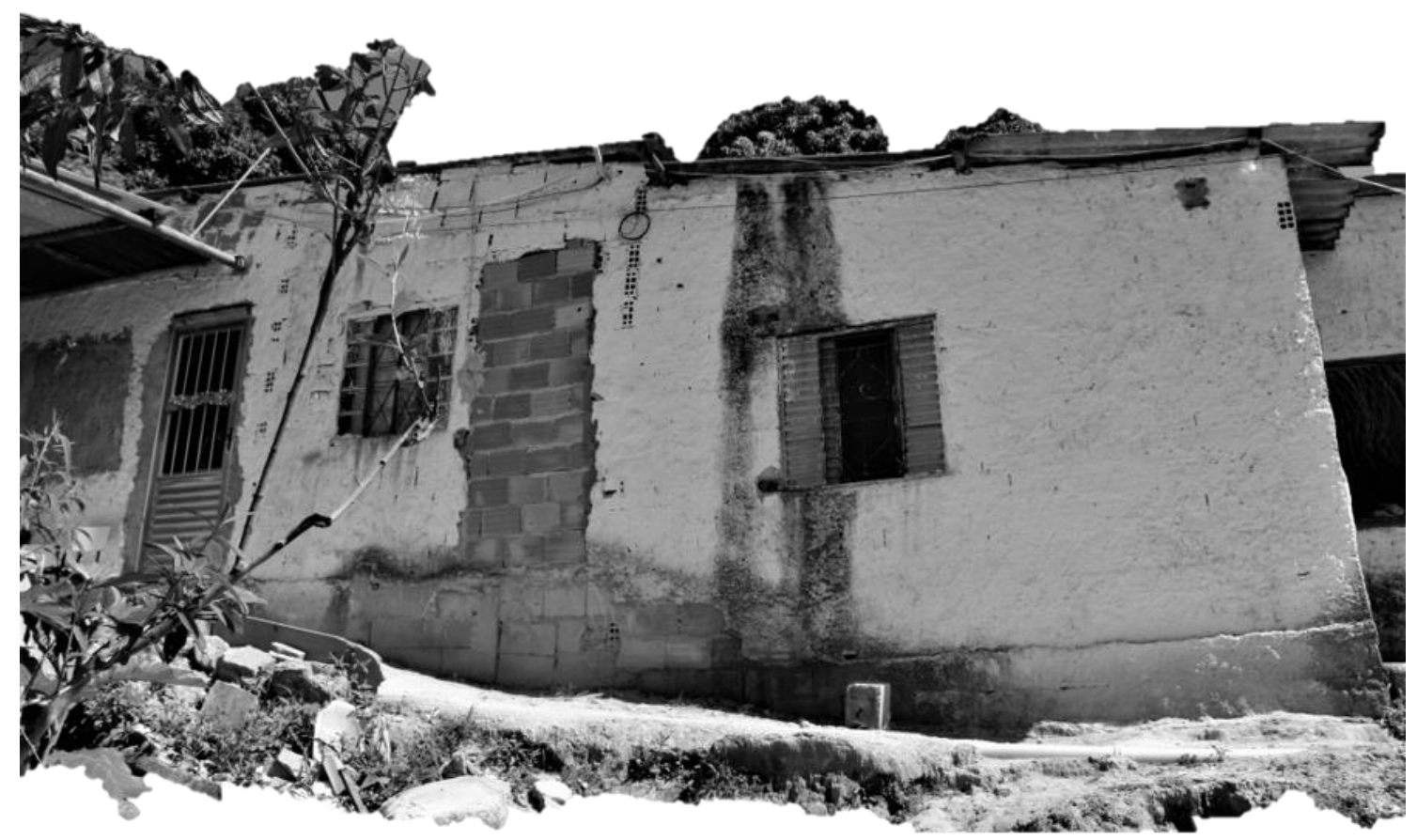

Figura 3- Colagem: "Fachada principal da casa de Mametu e uma parte do Barracão"

\section{Mãe Joana}

Mãe Joana ou Seciluanda, irmã carnal de Makota Cássia e filha consanguínea de Mametu Muiandê, conversava com seu outro irmão quando fui convidada a me aproximar, durante a pausa que deram na conversa. No silêncio que me recebeu, 
aguardei ela introduzir o diálogo, percebi que ela já sabia quem eu era então puxei assunto perguntando se todos moravam naquele espaço. Ela me respondeu gentilmente: "A nossa família é enorme, mas aqui, nessa área, aqui mora só a mãe e o marido dela. Aí ainda tem mais duas casas depois da casa da mãe. Uma mora a família da Bárbara e na outra, mora a família da Beatriz." - respectivas netas e suas famílias. Assim, comentei sobre a conversa que tive com sua irmã, Makota Cássia, onde ela falava sobre a arquivivência de sua mãe. E confirmou com orgulho: "É, minha mãe é uma grande arquiteta, tudo aqui que foi construído, saiu da cabeça dela. Ela sempre tem que ter um material de construção em casa, se ela não tiver, enlouquece todo mundo aqui", finalizou rindo e levantou me chamando para nos juntarmos à Makota Cássia e à Mametu na varanda de sua casa.

Quando chegamos, a matriarca me convidou para me sentar no pequeno banco ao lado e continuou a conversa com sua filha. Em uma das pausas, eu comentei com ela:

A: "Me disseram que a senhora é uma grande Arquiteta, que a senhora quem fez tudo isso aqui."

Mametu: "É minha filha, tudo foi eu quem fiz..."

A: "A senhora que bolou tudo?"

Mametu: "Eu que bolei tudo! Junto uns paus, pego umas telhas que estão sobrando e fiz essa varanda aqui."

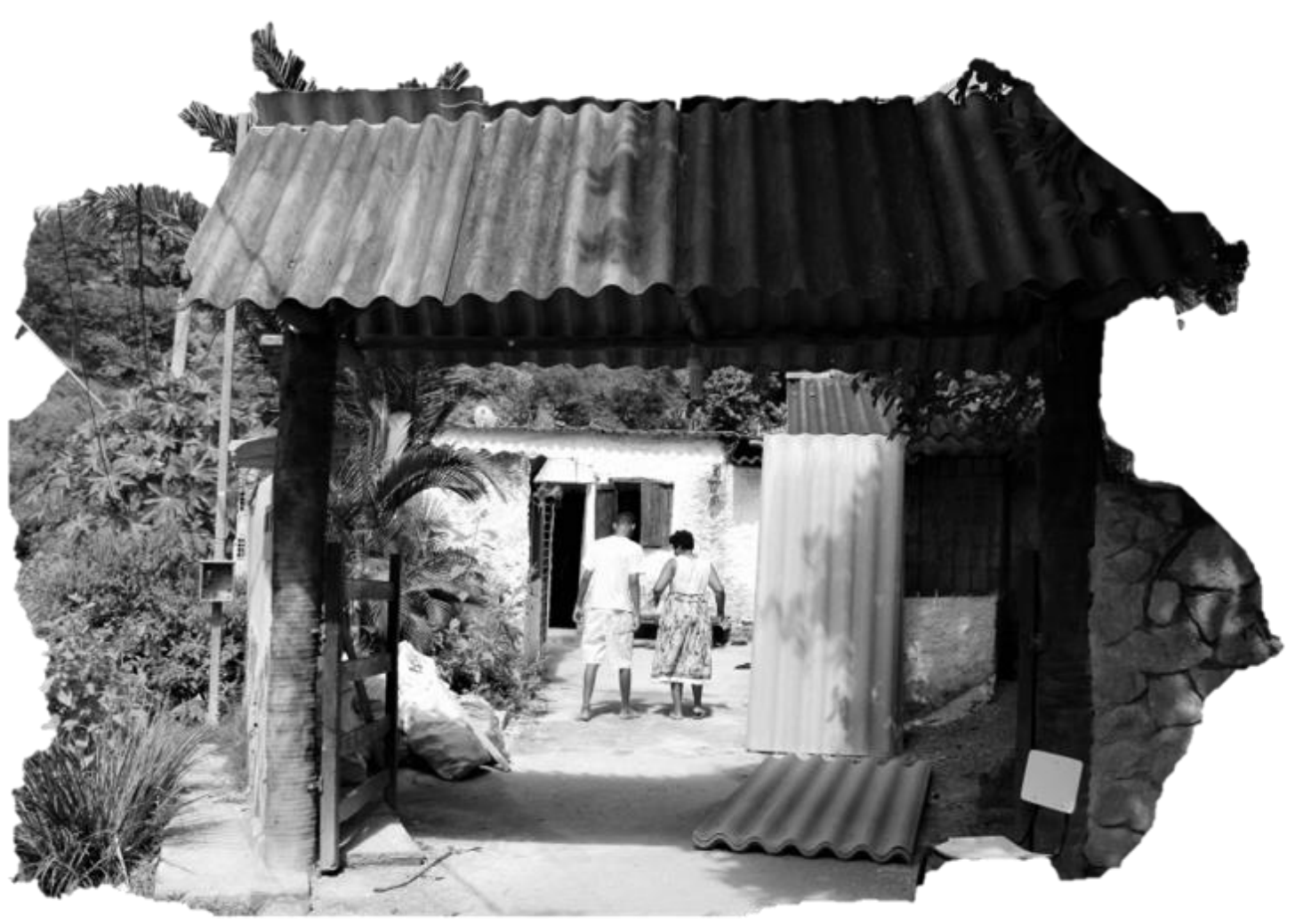

Figura 4- Colagem: "Entrada principal do terreiro Manzo e materiais de construção" 
Logo em seguida, as crianças que corriam em volta brincando de "imitar o santo" atravessaram a roda de conversa correndo e gritando e se mudou de assunto.

\section{Leve como brisa, intensa como tempestade, volátil como vento}

Nas tradições religiosas afro-brasileira, em específico as tradições advindas com os grupos Bantos ${ }^{9}$ - entre elas Tumba Junsara, Bate Folha, Bate Folhinha, entre várias outras, a divindade que representa entre muitas outras características ontológicas, a inquietude e a volatilidade, é chamada pelos candomblés de nação Angola de Matamba, Kayango ou Bamburucema. A brisa leve, o vento fresco que traz a chuva e o vento gelado que nos arrepia e pede respeito. O cata-vento muda de direção com o soprar do vento, como bem diz o saber popular, quando algo acontece de acordo com as expectativas projetadas: "Está de vento em popa". Assim me transpareceu ser Mametu Muiandê, cuja cabeça tem como divindade essa $\mathrm{Nkisse}^{10}$.

Observando as conversas que tínhamos em que muitas não eram conduzidas até o final por interferências externas ou pela própria natureza de sua fala, assim também se mostrou sua residência, sendo visível nas paredes internas e externas à casa, a quantidade de portas e janelas que foram realocadas. Demonstrando sua arquitetura espontânea e de "tecnologia africana". Não faço crítica de maneira alguma a essa maneira de viver e lidar com o espaço. Ao contrário disso, os diálogos e a percepção aqui expostos me fizeram compreender um pouco a lógica de convívio e habitat (HEIDEGGER, 1954; p.9). O espaço escrito e vivido por Mametu é um reflexo de sua natureza espontânea e inquieta.

Aos que chegaram até aqui, entendo que seja pertinente continuar a leitura na expectativa de alcançar uma conclusão que nos dê uma boa justificativa sobre o que me direcionou a observar como a residência de Dona Efigênia descreve seu modo de vida a partir de sua essência. Bem, a cerca de pouco mais de um ano, estudo esse terrei(tório) e escolhi expor a análise sobre essa residência a partir das conversas que tive com as interlocutoras supracitadas, e como dito, essa minha "análise" se baseia em demonstrar

\footnotetext{
${ }^{8}$ As crianças que crescem nesse contexto religioso costumam brincar de imitar "os santos" quando estão manifestados e seus filhos ficam em transe.

${ }^{9}$ Ver DIÉNE, Andréa Letícia Carvalho Guimarães et al. LÍNGUAS AFRICANAS NO PORTUGUÊS BRASILEIRO. Revista Calundu-Vol, v. 3, n. 1, 2019.

${ }^{10}$ Palavra de origem Banto, que se refere à Divindade para os candomblés de Nação Angola.
} 
como o espaço que vivemos ou a arquitetura que fazemos é (d)escrita ${ }^{11}$ por quem somos, pela característica ontológica que modela cada indivíduo.

As paredes que mudam de cor ou de lugar ao longo do tempo, os móveis que desenham o layout dos ambientes, as portas e janelas que mudam de lugar, todos esses aspectos físicos que se manifestam fenomenologicamente escrevem no espaço a personalidade de quem o habita. Quanto ao desfecho esperado para cada entrevista aqui narrada, deixo um trecho do relato da antropóloga Rita de Cássia Amaral descritas por Vagner Gonçalves da Silva como "algumas das situações pelas quais a maioria dos etnógrafos da área certamente já passou" no livro $O$ Antropólogo e sua Magia: Trabalho de Campo e Texto Etnográfico nas Pesquisas Antropológicas sobre Religiões Afro-brasileiras (SILVA, 2015). Um tanto cômico e exagerado sobre a paciência necessária - ou o tempo lido de maneira ocidental - para o pesquisar em terreiros de candomblé:

\begin{abstract}
Aí você vai naquela festa esperando, principalmente quando você é ingênuo e nunca foi, que o pai-de-santo vá falar com você, mas ele está ocupadíssimo, atendendo todo mundo e [...] cuidando das iniciações e você vai ficar lá só assistindo à festa. Sem contar que eles falam que a festa começa às oito horas da noite e começa à meia-noite (quando começa à meia-noite). Você fica lá e não pode ir embora porque você não sabe se pega mal ir embora antes que acabe. Além do mais, você é um pesquisador, então você tem que ver tudo. Então, você fica lá até as seis horas da manhã, quando vão servir o peixe ou qualquer coisa do tipo, que você não sabe se deve comer por causa da cara que aquela comida tem, queimada e esturricada, geralmente. (Então, quando te mandam comer obi, aquela coisa horrível, amarga, que você não suporta e não sabe se engole, se vai esperar cuspir.) E aí ele combina que você pode ir durante a semana e se você for muito legal ele vai te dar uma entrevista, onde ele vai mentir descaradamente durante duas horas na sua fita. É claro que ele não é obrigado a dizer nada para você, mas todo ritual acontece. Você vai ouvir, vai ficar cheio de dúvidas e aí você vai voltar para perguntar e ele vai ti contar outra história completamente diferente. Em geral vai falar mais sobre a casa dos outros, e assim o conhecimento é sempre diagonal. Você entrevista um e aprende sobre o outro. Até você perceber que isto pode se tornar uma estratégia, a impressão é de perda de tempo e energia. Eu passei por isso várias vezes... Acho que depois você acostuma [...] porque se você está no grupo você sabe qual é a lógica e tem que se submeter a ela se quiser estudar candomblé (SILVA, 1998; p.43).
\end{abstract}

\footnotetext{
${ }^{11}$ Aglutinação das palavras "descrita" e "escrita". Uma brincadeira com que é narrado/descrito e o que é escrito/transposto/impresso nas paredes da casa.
} 


\section{Referências Bibliográficas}

ALMEIDA, Alfredo Wagner Berno de. "Os quilombos e as novas etnias". In: Quilombos: identidade étnica e territorialidade. Rio de Janeiro: Editora FGV, p. 43-81, 2002.

DIÉNE, Andréa Letícia Carvalho Guimarães et al. "Línguas africanas no português brasileiro". In: Revista Calundu - Vol, v. 3, n. 1, 2019.

DIÉNE, A. A. L.; AHUALLI, I. F. LUGAR DE MAIS VELHXS - Uma observação fenomenológica dos limites espaciais no terreiro de candomblé Tumba Nzo Jimona dia Nzambi. 2019.

EVARISTO, Conceição. Becos da memória. Pallas Editora, 2017.

FABIAN, Johannes. "O tempo e o outro emergente". In O Tempo e o Outro: como a antropologia estabelece seu objeto. Petrópolis: Vozes. Pp. 39- 70, 2013 [1983].

HEIDEGGER, Martin. Construir, Habitar, Pensar. [Bauen, Wohnen, Denken] Trad. de Marcia Sá Cavalcante Schuback (1951) conferência pronunciada por ocasião da" Segunda Reunião de Darmastad", publicada em Vortäge und Aufsätze, G. Neske, Pfullingen, 1954.

MALINOWSKI, Bronislaw. Argonautas do Pacífico Ocidental. São Paulo: Abril Cultural, 1976 [1922]

MARQUES, Carlos Eduardo et al. Bandeira Branca em Pau Forte: a Senzala de Pai Benedito e o Quilomblé urbano de Manzo Ngunzo Kaiango. 2015.

SEGAUD, Marion. Antropologia do espaço: habitar, fundar, distribuir, transformar. São Paulo: SESC São Paulo, 2016.

SILVA, Vagner Gonçalves da. O Antropólogo e sua Magia: Trabalho de Campo e Texto Etnográfico nas Pesquisas Antropológicas sobre Religiões Afro-brasileiras/ Vagner Gonçalves da Silva. $-1^{\circ}$ ed., $2^{\mathrm{a}}$ reimp. - São Paulo: Editora da Universidade de São Paulo, 2015.

RATTS, Alex. Eu sou atlântica. Sobre a trajetória de vida de Beatriz Nascimento. São Paulo: Instituto, 2006.

Recebido em: 07/05/2020

Aceito em: 10/05/2020 